\title{
Asterixis and dysarthria-clumsy hand originated of lacunar infarction: A series of six cases
}

\author{
Asterixis y disartria-mano torpe originado a partir de los infartos lacunares: \\ Una serie de seis casos
}

Juan Montalvo-Herdoíza, ${ }^{1}$ Daiane Bittencourt-Fraga, ${ }^{2}$ Gilberto Vizcaíno, ${ }^{1,3}$ Aline Siteneski ${ }^{1,3}$

\begin{abstract}
Asterixis and dysarthria-clumsy hand are uncommon neurological signs following to movement disorders after a stroke, clinically are classified as a part of lacunar infarction and most of the cases resolved spontaneously within ten days to one month. The aim of this study was to describe the clinical characteristics of six patients with lacunar infarction and mild motor symptoms of dysarthria and asterixis with no signs of dementia. All patients had as comorbidities hypertension and/or type 2 diabetes. In conclusion, it is important due to the transience of the abnormal neurological movements, the promptly recognition of the characteristic clinical presentation and confirmation of the diagnosis with noninvasive studies. The patients should be treated to prevent recurrent stroke with more severe consequences.

Keywords: Asterixis, dysarthria-clumsy hand, lacunar infarction, stroke

\section{Resumen}

La asterixis y la disartria-mano torpe son signos neurológicos poco frecuentes que pertenecen a los trastornos del movimiento después de un accidente cerebrovascular. Clínicamente ellos son clasificados como parte del infarto lacunar y la mayoría de los casos se resuelven espontáneamente en un periodo entre 10 semanas y un mes. El objetivo de este estudio fue reportar seis casos de pacientes masculinos con infarto lacunar y describir los síntomas, localización y tamaño de las lesiones. Se describen casos de infarto lacunar y síntomas motores leves (disartria y asterixis) sin ningún indicio de demencia. En conclusión, nuestros casos presentan movimientos neurológicos anormales como asterixis y disartria-mano torpe en pacientes con hipertensión y / o diabetes mellitus tipo 2. Debido a la transitoriedad de esos movimientos, el diagnóstico en el tiempo adecuado es importante, a partir de eso los médicos pueden solicitar los exámenes de imagen, tratar al paciente y luego acompañarlo previniendo futuros ictus con consecuencias aún más graves. Así, estudios como el nuestro pueden contribuir al correcto diagnóstico de los infartos lacunares.

Palabras clave: Asterixis, disartria-mano torpe, infarto lacunar, accidente cerebrovascular
\end{abstract}

Rev. Ecuat. Neurol. Vol. 30, Nº 3, 2021

\section{Introduction}

Cerebrovascular accidents (stroke) are the second leading cause of death in the word. ${ }^{1}$ Lacunar infarction accounts for about $20 \%$ of all strokes and are caused mainly by smallvessel disease occluding a small perforating artery.,3 A lacune usually describes as small perforating arteries feeding deep subcortical structures. Lacunes of presumed vascular origin are shaped as a round or ovoid, subcortical, fluid-filled cavities, with $3 \mathrm{~mm}$ and about $15 \mathrm{~mm}$ in diameter. Risk factors for lacunar infarction includes age, gender, hypertension, diabetes, previous transient ischaemic attack, and possibly ischaemic heart disease, ${ }^{5,6}$ others risk factors such as cardiac or carotid emboli have been suggested as possible cause of lacunar infarction. Clinically, lacunar infarction can manifest with several syndromes depending on the lesion location, usually are small infarcts in the deep cerebral white matter, basal ganglia or pons. ${ }^{8}$ Five symptomatic signals are well recognized such as: pure motor hemiparesis, sensorimotor stroke, pure sensory stroke, dysarthria-clumsy hand and ataxic hemiparesis., ${ }^{6-11}$
'Faculty of Health Sciences, Universidad Técnica de Manabí, 130101, Portoviejo, Ecuador.

${ }^{2}$ University Massachussets of Amherst, 01003, Massachussets, EUA.

${ }^{3}$ Scientific Research Institute, Universidad Técnica de Manabí, 130103,

Portoviejo, Manabí, Ecuador.
Corresponding author:

Dr. Aline Siteneski, Ph.D.

Scientific Research Institute, Universidad Técnica de Manabí

Phone: (+593) 052657109

E-mail: aline.siteneski@gmail.com 
Neurological progression is one of the major problems in managing the patients with acute lacunar infarction usually developed within hours or a few days following the acute lacunar infarction event and typically involved primarily motor function. ${ }^{12,13}$ Curiously, until $20 \%$ of asymptomatic elderly persons have evidence of incidental lacunes in image studies. ${ }^{14}$ Investigations have focused on the dysfunction of the autonomic nervous system as a cause of neurological progression. ${ }^{15}$ However, just few studies were performed describing abnormal involuntary and transient movements as asterixis and dysarthria-clumsy hand, as a consequence of lacunar infarction.,16-18 The aim of this study was to report six cases of male patients with lacunar infarction and mild motor symptoms of dysarthria and asterixis with a description of the symptoms, localization, and size of the lesions.

\section{Patients' presentations and neuroradiological diagnosis}

The clinical history of each patient was fulfilled according to the CARE guidelines checklist for case report. ${ }^{19}$

First patient (Figure $1 \mathrm{~A}$ ): a 56-years-old man with history of type 2 diabetes and a severe uncontrolled hypertension. The patient presented with dysarthria and clumsy hand eight years ago, diagnosed with Weber syndrome and magnetic resonance imaging (MRI) showed in the flair sagittal section, a lacunar infarction in the right semioval center of $12 \mathrm{~mm}$ in diameter and in the sagittal T1 an infarct in the right cerebral peduncle of the midbrain with a diameter of $15 \mathrm{~mm}$ (Figure 1 B).

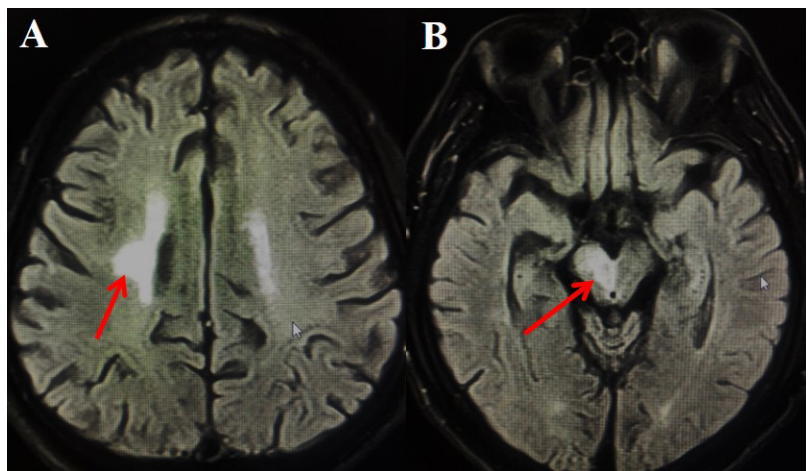

Figure 1. MRI image of a patient with clumsy- hand. Figure A shows a flair axial section with a lacunar infarction in the right semioval center, $12 \mathrm{~mm}$ diameter. Figure $1 \mathrm{~B}$ shows infarct in the right cerebral peduncle of the midbrain, $15 \mathrm{~mm}$ diameter.

Second patient (Figure 2 A): a 65-years-old man, smoker, history of type 2 diabetes, moderate hypertension, and a history of previous myocardial infarction. The patient has symptoms of dysarthria-clumsy hand and headache, the MRI images exams show in coronal flair section, an $8 \mathrm{~mm}$ diameter lacunar infarct in the left semioval center.
The third patient represent a 55-years-old man (Figure 2 B). Patient with dysarthria during workday. Besides that, he had moderate uncontrolled arterial hypertension. Small $3 \mathrm{~mm}$ diameter pons lacunar infarct was revealed in the sagittal section MRI.

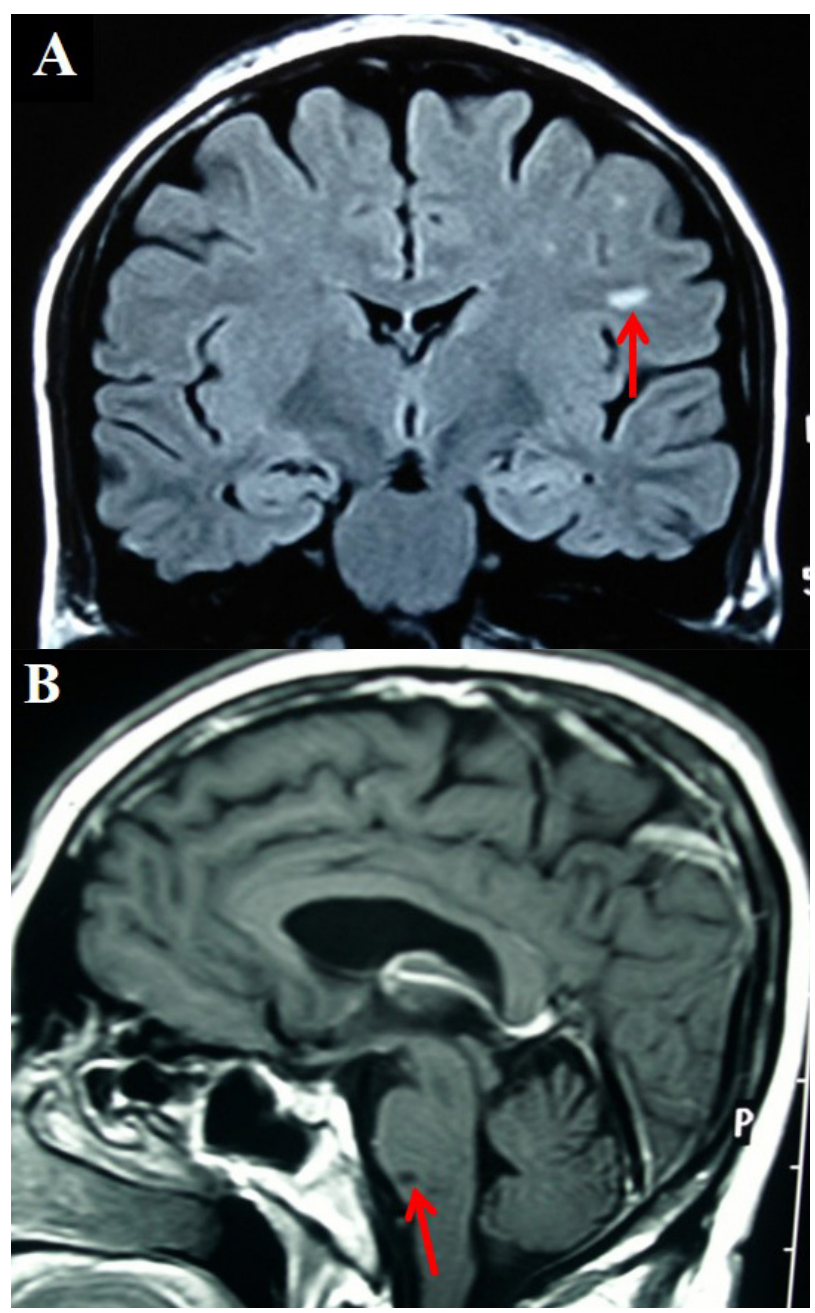

Figure 2. Two patients with dysarthria clumsy hand in MRI images exams. Figure $2 \mathrm{~A}$ shows coronal flair section with an $8 \mathrm{~mm}$ diameter lacunar infarct in the left semioval center. Figure $2 B$ shows a sagittal section with a $3 \mathrm{~mm}$ lacunar infarct in thepons.

The fourth patient is a 59-years-old man with severe arterial hypertension and diabetes mellitus. Figure 3 shows a lacunar infarct in the coronal $\mathrm{T} 2$ section, $10 \mathrm{x} 4 \mathrm{~mm}$ at the junction of the pons with the left posterior midbrain area.

The fifth case showed symptoms of left asterixis and facio-brachio-crural hemiparesis in a 65 -year-old male with smoking history, type 2 diabetes mellitus, hypertension, and atrial fibrillation. A brain CT scan in cross section showed a lacunar $10 \mathrm{~mm}$ infarct in the right internal capsule (Figure 4 A). 


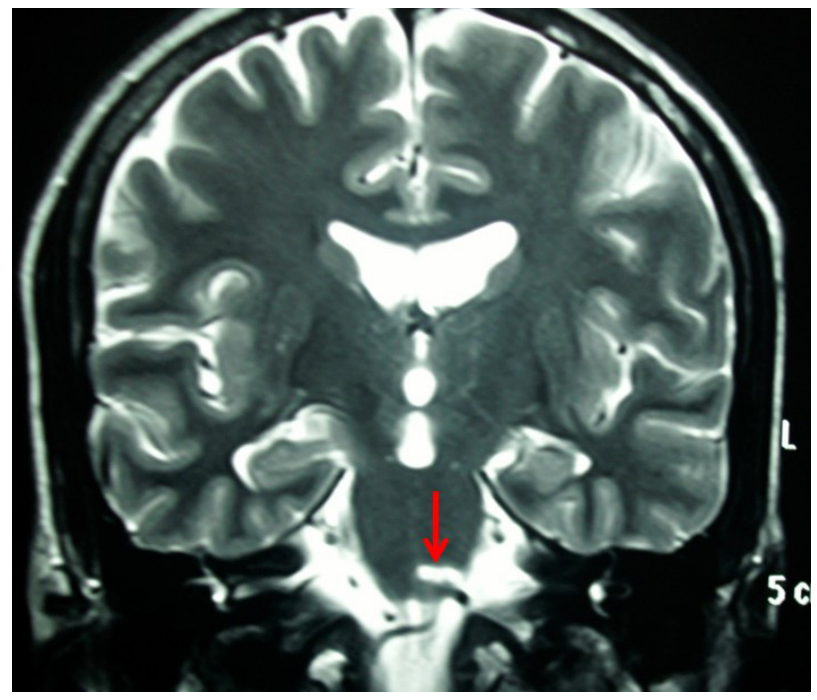

Figure 3. MRI image shows a male patient with clinical symptoms of dysarthria-clumsy hand and asterixis. Lacunar infarction in the T2 coronal section shows a longitudinal lacunar infarct of $10 \times 4 \mathrm{~mm}$ in the lower pons.

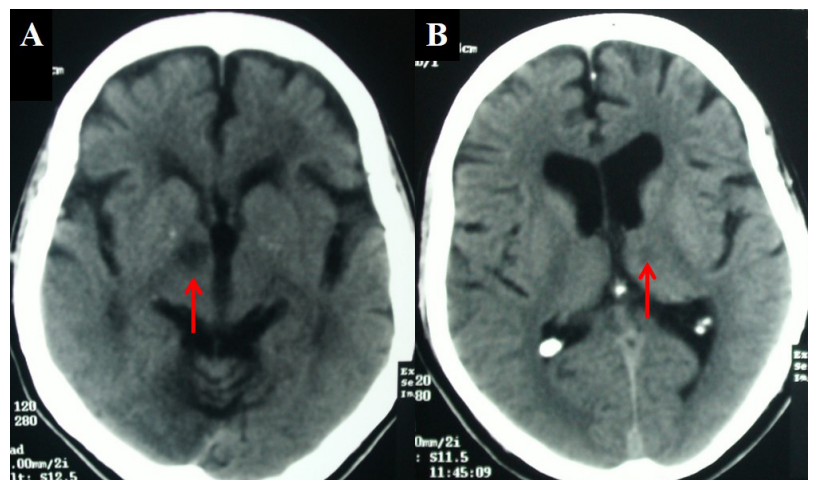

Figure 4. A brain CT scan represent two patients with asterixis. Figure $A$ cross section shows a lacunar infarct of $10 \mathrm{~mm}$ in diameter in the right internal capsule. The figure $4 \mathrm{~B}$ shows a lacunar infarct $8 \mathrm{~mm}$ diameter at the anterior pole of the left thalamus.
Sixth case (Figure $4 \mathrm{~B}$ ) belongs to a 70-year-old man with type 2 diabetes and moderate hypertension, right asterixis and clumsy hand. Brain $\mathrm{CT}$ in cross section showed a lacunar $8 \mathrm{~mm}$ infarct at the anterior pole of the left thalamus.

All these results are resumed in table 1.

In these patients the treatment was dual antiplatelet therapy (DAPT; clopidogrel-aspirin) and orientation in controlling modifiable risk factors.

\section{Discussion}

Asterixis and dysarthria-clumsy hand syndrome is well known but infrequent lacunar syndrome. In this report, lacunar infarctions are presented in elderly adults (56-70-years-old) with hypertension and type 2 diabetes as comorbidities. Lacune of presumed vascular origin are associated with an increased risk of stroke, gait impairment, dementia, and commonly it is seen on imaging of elderly patients with no symptoms. ${ }^{20,21}$ Interestingly, Fischer and colleagues described in the midbrain not to have typical lacunes in some cases, ${ }^{3}$ but in this work we describe common sites lacune of presumed vascular origin as pons, white matter and thalamus. Hypertension is a significant risk factor for lacunar stroke compared with non-lacunar ischemic stroke. ${ }^{22-24}$

The main clinical comorbidities observed in this case series were elderly patients with hypertension, diabetes and smoking. The hypertension is the most important and prevalent risk factor for stroke. ${ }^{25,26}$ Evidence has shown that patients without diabetes, lowering blood pressure reduces the stroke. ${ }^{27}$ However, a systolic blood pressure of $<120 \mathrm{mmHg}$ when compared with $<140$ $\mathrm{mmHg}$, had a non-significant $11 \%$ lower incidence of stroke in patients at high risk for cardiovascular events. ${ }^{28}$ In the present study, all reported cases had a clear history of hypertension. Two reported cases with hypertension

Table 1. Clinical and lesions characteristics of patients with lacunar infarctions.

\begin{tabular}{|c|c|c|c|c|c|}
\hline $\begin{array}{l}\text { Case } \\
\text { Report }\end{array}$ & Years & Characteristic & Clinical symptoms & Location of lesion & Size of lesion \\
\hline 1 & 56 & $\begin{array}{l}\text { Type } 2 \text { diabetes, } \\
\text { uncontrolled hypertension }\end{array}$ & $\begin{array}{l}\text { Dysarthria clumsy- hand. Antecedent of ischemic } \\
\text { injury in synovial center (Weber syndrome) }\end{array}$ & $\begin{array}{l}\text { Midbrain } \\
\text { Right semioval center. }\end{array}$ & $\begin{array}{l}15 \mathrm{~mm} \\
12 \mathrm{~mm}\end{array}$ \\
\hline 2 & 65 & $\begin{array}{l}\text { Type } 2 \text { diabetes } \\
\text { arterial hypertension } \\
\text { smoker Myocardial infarction }\end{array}$ & Dysarthria clumsy- hand Headache & $\begin{array}{l}\text { Left semioval center } \\
\text { (white matter underneath } \\
\text { cortex) }\end{array}$ & $8 \mathrm{~mm}$ \\
\hline 3 & 55 & arterial hypertension & Dysarthria and clumsy hand & Pons & $3 \mathrm{~mm}$ \\
\hline 4 & 59 & $\begin{array}{l}\text { Type } 2 \text { diabetes, } \\
\text { arterial hypertension }\end{array}$ & Dysarthria, clumsy hand and Asterixis & Between pons and midbrain & $10 \times 4 \mathrm{~mm}$ \\
\hline 5 & 65 & $\begin{array}{l}\text { Type } 2 \text { diabetes } \\
\text { arterial hypertension } \\
\text { smoker atrial fibrillation }\end{array}$ & $\begin{array}{l}\text { Unilateral Asterixis Hemiparesis } \\
\text { Facio-brachio-crural }\end{array}$ & Right internal capsule & $10 \mathrm{~mm}$ \\
\hline 6 & 70 & $\begin{array}{l}\text { Type } 2 \text { diabetes } \\
\text { arterial hypertension }\end{array}$ & $\begin{array}{l}\text { Unilateral asterixis (right) } \\
\text { Dysarthria, clumsy hand }\end{array}$ & Anterior pole thalamus & $8 \mathrm{~mm}$ \\
\hline
\end{tabular}


were also smokers. Cigarette smoking increases risk of all ischemic strokes, including lacunes and this fact has been well documented, ${ }^{29-31}$ likewise, the major risk factors for the increased severity of lacunes is significantly higher when lifestyle is associated with hypertension. ${ }^{32-34}$ In fact, hypertension is known to increase the risk of lacunar stroke in until 8.9 times. $^{32}$ Furthermore, studies reported that diabetes and hypertension were factors related to the recurrence and multiple lacunar infarcts of lacunar stroke in patients. ${ }^{22,32,35}$ Recurrent strokes were more likely to be lacunar if the patient presented the first event as lacunar. ${ }^{36}$

Diabetes may be an important risk factor to lacunar disease. ${ }^{37}$ Almost all the reported cases in this study are associated with diabetes and hypertension comorbidities. According to a cross-sectional study, these comorbidities increased the potential risk for development a lacunar infarction in patients $3^{38}$ Harvard Cooperative and Aboix et al., showed that $29 \%$ and $28 \%$ (respectively) of lacunar diagnosed cases were from patients with diabetes. $^{39,40}$ Moreover, smaller lacunes may be associated with diabetes and glycated hemoglobin. ${ }^{41}$ We observed in this study that diabetics patients presented up to $15 \mathrm{~mm}$ lacunes in midbrain, white matter, and thalamus. As previously indicated, diabetic patients with recent lacunar stroke have a distinctive neuroimaging characteristic on MRI scan as compared with those without diabetes and increased the incidence of posterior circulation infarcts but a lower burden of microbleeds and enlarged perivascular spaces. ${ }^{42,43}$

Epidemiological studies reported that survival after lacunar infarcts is greater among patients suffering lacunar infarctions compared with those with non-lacunar infarcts. ${ }^{44,45}$ The consequences of lacunar infarction are cognitive impairment and dementia; these incidental lacunes double and more the risk of subsequent stroke and dementia. ${ }^{14,19} \mathrm{Up}$ to $20 \%$ of asymptomatic elderly persons have evidence of incidental lacunes on MRI scan.${ }^{14}$ Curiously, here we observed older people with lacunar infarction and mild motor symptoms (dysarthria and asterixis) without any symptoms of dementia.

Although the terminology of "lacunar infarction" a recent subcortical infarction does not always lead to a lacune in long-term follow-up. The small subcortical infarcts may occur in the perfusion territory of a small artery or arteriole penetrating the internal part of the brain (ie, cavities).,46,47 The terminology lacune of presumed vascular origin characterized by a round or ovoid, subcortical, fluid-filled cavity (signal similar to CSF) between $3 \mathrm{~mm}$ and $15 \mathrm{~mm}$ diameter, consistent with a previous acute small subcortical infarct or hemorrhage in the territory of one perforating arteriole. The cause of most lacunes is presumed to be small subcortical infarcts, either symptomatic or silent that present many different clinical symptoms, including asterixis and dysarthria are associated.116,17 Both neurological signs were confirmed in this report. Our related cases reinforce the hypothesis that risk factors as diabetes and hypertension added to the sensory motor symptoms may be an indicator of subsequent lacunar stroke occurrence.

In this study, we reported a case of thalamus lacunar infarction that was accompanied by unilateral asterixis. Asterixis or negative myoclonus occurs when a muscle contraction is suddenly interrupted. Usually, this involuntary movement is bilateral and accompanied by metabolic encephalopathy! ${ }^{18,48,49}$ A study of 30 cases of unilateral asterixis revealed a prevalence of $1.9 \%$ focal post-stroke brain lesion, 19 of these patients presented thalamic lesions. ${ }^{17}$ These abnormal involuntary movements are often transient (lasting from 2 to 12 days) and induced by contralateral lesions involving the thalamic ventrolateral and ventroposterior nucleus. ${ }^{48}$ Asterixis may be mediated by the sensorimotor cortex rendered in an excessive inhibition as result of the thalamic lesion. ${ }^{49}$ Unilateral asterixis has been reported in patients with thalamic lesion, ${ }^{50,51}$ uncommonly is related in lacunar infarction outset. ${ }^{16,18}$ Curiously, in our study, the classic characteristics of anterior thalamic infarction as neuropsychological deficits or altered levels of consciousness in early stages ${ }^{52}$ or thalamic pain syndrome ${ }^{53}$ were not detected in any patient. The reported cases in this study, the imaging exams of thalamic anterior lacunar infarction was accompanied by clinical manifestation of asterixis and dysarthria-clumsy hand. Although asterixis symptoms occurs because of thalamic injury, ${ }^{49}$ further work is needed to understand the underlying motor symptoms mechanisms as injuries of small lacunar infarctions.

Dysarthria-clumsy hand is the most uncommon of all lacunar syndromes, affecting between 2 and $6 \%$ of lacunar strokes. ${ }^{40,54}$ Generally, these abnormalities occur due to a focal lesion in the basal ganglia causing damage to corticofugal fibers adjacent to axons of pontine neurons ${ }^{55,56}$ We reported five cases with dysarthria symptom and history of hypertension; these clinical symptoms developed abruptly in the setting of hypertension. ${ }^{39,54}$ From the imaging studies (TC/MRI) it is possible to appreciate a small, deep infarction in a penetrating vessel territory reflecting an internal capsule or pons lesion. Regarding the possible location of lacunar infarctions with clinical consequence of dysarthria-clumsy hand, the encephalic pons is the most frequently site generating this clinical symptom., ${ }^{9,54}$ Our results described one case of hypertension with lacunar infarct in the pons with dysarthria-clumsy hand, and other case with a lesion between pons and midbrain. In addition, in a study evaluating 35 patients with dysarthria-clumsy hand syndrome, $17 \%$ showed a pons lacunar infarct. ${ }^{54}$

Moreover, we reported one patient with lacunar 
lesion in centrum semiovale. This region is supplied by the medullary artery of Duret, that comes off pial branches of the middle cerebral artery. This characteristic is suggested to be prone to embolism from large artery or perfusion failure, or atheromatous disease of the branch arteries. ${ }^{58}$ However, some evidence controversy about infarcts in the centrum semiovale may be found in the magnetic resonance (MR) definition of lacunar infarct, ${ }^{4,59}$ while other studies have supported that infarct in this location have lacunar mechanism., ${ }^{4,906-62}$ White matter has a characteristic in the blood flow, known as watershed effect. This condition is the most vulnerable to suffer hypoxia/hypoperfusion. ${ }^{63}$ Besides that, white matter hyperintensities may origin from several factors, such as demyelination, caused by chronic diffuse hypoperfusion or reduced cerebral blood flow, to break down of the blood-brain barrier, disturbances of small blood vessels, glial activation or loss of oligodendrocytes and small infarcts in the white matter. ${ }^{63-65}$ In this study, MRI and CT showed lacunar infarction with a diameter between 8 and $15 \mathrm{~mm}$.

The principal limitation of this study is lacking follow up of the patient's clinical course. This may be due to the fact that the patient, once diagnosed and placed in treatment, does not attend subsequent evaluations. As these lesions are mostly benign, the patient fully recovers and does not return to a subsequent appointment. On the other hand, there may be an under reporting of abnormal movements in the acute phase of stroke due to late presentation of patients to the healthcare facility. Another explanation may be a recall bias due to poor memory of the presence of abnormal movements in the acute phase of stroke, focusing on the more pronounced neurological manifestations and subtle asterixis or dysarthria-clumsy hand may not be noticed.

\section{Conclusion}

The report of a series of cases with intrinsic association between the presence of asterixis and dysarthriaclumsy hand as symptoms of ischemic lacunar infarction are presented here. The present work highlights the importance of considering abnormal neurological movements as a possible diagnosis of lacunar infarctions. Although asterixis and dysarthria-clumsy hand do not belong exclusively to the lacunar syndromes, they must be taken into consideration by the physicians. Due to the transience of these movements, the diagnosis at the appropriate time is essential, to obtain prompt exams, give adequate treatment, and prevent future strokes. These case series can contribute to the proper diagnosis of lacunar infarctions.

\section{References}

1. Regenhardt RW, Das AS, Stapleton CJ, Chandra R V., Rabinov JD, Patel AB, et al. Blood pressure and penumbral sustenance in stroke from large vessel occlusion. Front Neurol. 2017;8(6):317. https://doi. org/10.3389/fneur.2017.00317

2. De Jong G, Kessels F, Lodder J. Two types of lacunar infarcts: Further arguments from a study on prognosis. Stroke. 2002;33(8):2072-6. https://doi.org/10.1161/01. STR.0000022807.06923.A3

3. Caplan LR. Lacunar Infarction and Small Vessel Disease: Pathology and Pathophysiology. J stroke. 2015;17(1):2-6. https://doi.org/10.5853/jos.2015.17.1.2

4. Wardlaw JM, Smith EE, Biessels GJ, Cordonnier C, Fazekas F, Frayne R, et al. Neuroimaging standards for research into small vessel disease and its contribution to ageing and neurodegeneration. Lancet Neurol. 2013;12(8):822-38. https://doi.org/10.1016/S14744422(13)70124-8

5. Lodder J, Bamford JM, Sandercock PAG, Jones LN, Warlow CP. Are hypertension or cardiac embolism likely causes of lacunar infarction? Stroke. 1990;21(3):375-81. https://doi.org/10.1161/01. STR.21.3.375

6. Norrving B, Staaf G. Pure Motor Stroke from Presumed Lacunar Infarct. Cerebrovasc Dis. 1991;1(4):203-9. https://doi.org/10.1159/000108843

7. Del Bene A, Makin SDJ, Doubal FN, Inzitari D, Wardlaw JM. Variation in risk factors for recent small subcortical infarcts with infarct size, shape, and location. Stroke. 2013;44(11):3000-6. https://doi. org/10.1161/STROKEAHA.113.002227

8. Lammie GA. Pathology of small vessel stroke. Br Med Bull. 2000;56(2):296-306. https://doi. org/10.1258/0007142001903229

9. Fisher CM. Lacunar strokes and infarcts: A review. Neurology. 1982;32(8):871-6. https://doi.org/10.1212/ wnl.32.8.871

10. Norrving B. Long-term prognosis after lacunar infarction. Lancet Neurol. 2003;2(4):238-45. https:// doi.org/10.1016/S1474-4422(03)00352-1

11. Fisher CM. Lacunar infarcts. A review. Cerebrovasc Dis. 1991;1:311-20.

12. Ohara T, Yamamoto Y, Tamura A, Ishii R, Murai T. The infarct location predicts progressive motor deficits in patients with acute lacunar infarction in the lenticulostriate artery territory. J Neurol Sci. 2010;293(12):87-91. https://doi.org/10.1016/j.jns.2010.02.027

13. Park JH, Kim IH, Ahn JH, Noh Y, Kim SS, Lee TK, et al. Pretreated Oenanthe Javanica extract increases anti-inflammatory cytokines, attenuates gliosis, and protects hippocampal neurons following transient global cerebral ischemia in gerbils. Neural Regen Res. 2019;14(9):1536-43. https://doi.org/10.4103/16735374.255973 
14. Nam KW, Kwon HM, Lim JS, Han MK, Nam H, Lee YS. The presence and severity of cerebral small vessel disease increases the frequency of stroke in a cohort of patients with large artery occlusive disease. PLoS One. 2017;12(10):1-12. https://doi.org/10.1371/ journal.pone. 0184944

15. Ha SY, Park KM, Park J, Kim SE, Lee BI, Shin KJ. Autonomic function test in progressive lacunar infarction. Acta Neurol Scand. 2018;138(1):32-40. https://doi.org/10.1111/ane.12913

16. Shuttleworth, C Edwin; Drake EM. Asterixis after lacunar infarctions. 1987;27:62-3. https://doi.org/doi: 10.1159/000116131

17. Kim JS. Asterixis after unilateral stroke: Lesion location of 30 patients. Neurology. 2001;56(4):533-6. https://doi.org/10.1212/WNL.56.4.533

18. Lazzarino LG, Nicolai A. Late onset unilateral asterixis secondary to posterior cerebral artery infarction. Ital J Neurol Sci. 1992;13(4):361-4. https://doi. org/10.1007/BF02223104

19. Gagnier, J. J., Kienle, G., Altman, D. G., Moher, D., Sox, H., Riley, D., \& CARE Group. The CARE guidelines: consensus-based clinical case report guideline development. J Diet Suppl. 2013;10(4):381-390. https://doi.org/10.7453/gahmj.2013.008

20. Vermeer SE, Prins ND, Den Heijer T, Hofman A, Koudstaal PJ, Breteler MMB. Silent brain infarcts and the risk of dementia and cognitive decline. $\mathrm{N} \mathrm{Engl}$ J Med. 2003;348(13):1215-22. https://doi.org/10.1056/ NEJMoa022066

21. Snowdon DA, Greiner LH, Mortimer JA, Riley KP, Greiner PA MW. Brain infarction and the clinical expression of Alzheimer disease. JAMA J Am Med Assoc. 1997;277:813-7. https://doi.org/10.1001/ jama.1997.03540340047031

22. Jackson C, Sudlow C. Comparing risks of death and recurrent vascular events between lacunar and non-lacunar infarction. Brain. 2005;128(11):2507-17. https://doi.org/10.1093/brain/awh636

23. Khan U, Porteous L, Hassan A, Markus HS. Risk factor profile of cerebral small vessel disease and its subtypes. J Neurol Neurosurg Psychiatry. 2007;78(7):702-6. jnnp.2006.103549

24. Hilal S, Mok V, Youn YC, Wong A, Ikram MK, Chen CLH. Prevalence, risk factors and consequences of cerebral small vessel diseases: Data from three Asian countries. J Neurol Neurosurg Psychiatry. 2017;88(8):669-74. https://doi.org/10.1136/jnnp2016-315324

25. Eggers CCJ, Bocksrucker C, Seyfang L. The efficacy of thrombolysis in lacunar stroke - evidence from the Austrian Stroke Unit Registry. Eur J Neurol. 2017;24(6):780-7. https://doi.org/10.1111/ene.13288

26. Arboix A, Massons J, García-Eroles L, Grau-Olivares M, Targa C, Comes E, et al. Variaciones en el perfil clínico y pronóstico de las hemorragias intracerebrales no traumáticas (1986-2004). Med Clin (Barc). 2014;142(1):1-6. https://doi.org/10.1016/j. medcli.2013.03.017

27. Benavente O, Coffey C, Conwit R, Hart R, McClure L, Pearce L, et al. Effects of Blood Pressure Targets in Patients with Recent Lacunar Stroke: the SPS3 randomised trial. Lancet. 2013;382(9891):507-15. https:// doi.org/10.1016/S0140-6736(13)60852-1

28. SPRINT Research Group, Wright JT Jr, Williamson JD, Whelton PK, Snyder JK, Sink KM, Rocco MV, Reboussin DM, Rahman M, Oparil S, Lewis CE, Kimmel PL, Johnson KC, Goff DC Jr, Fine LJ, Cutler JA, Cushman WC, Cheung AK AW. A Randomized Trial of Intensive versus Standard Blood-Pressure Control. N Engl J Med. 2015;173(22):2013-6. https:// doi.org/10.1056/NEJMoa1511939

29. Donnan GA, Adena MA, Malley HMO, Mcneil JJ, Doyle AE, Neill GC. Smoking as a risk factor for cerebral ischaemia. Lancet. 1989;643-7. https://doi. org/doi: 10.1016/s0140-6736(89)90894-5.

30. Mannami T, Iso H, Baba S, Sasaki S, Okada K, Konishi M, et al. Cigarette smoking and risk of stroke and its subtypes among middle-aged Japanese men and women: The JPHC study cohort I. Stroke. 2004;35(6):1248-53. https://doi.org/10.1161/01. STR.0000128794.30660.e8

31. Tanizaki Y, Kiyohara Y, Kato I, Iwamoto H, Nakayama K, Shinohara N, et al. Incidence and risk factors for subtypes of cerebral infarction in a general population: The Hisayama study. Stroke. 2000;31(11):261622. https://doi.org/10.1161/01.STR.31.11.2616

32. You R, McNeil JJ, O'malley HM, Davis SM, Donnan GA. Risk factors for lacunar infarction syndromes. Neurology. 1995;45(8):1483-7. https://doi.org/10.1212/ WNL.45.8.1483

33. Howard G, Wagenknecht LE, Cai J, Cooper L, Kraut MA, Toole JF. Cigarette smoking and other risk factors for silent cerebral infarction in the general population. Stroke. 1998;29(5):913-7. https://doi. org/10.1161/01.STR.29.5.913

34. Longstreth WT, Bernick C, Manolio TA, Bryan N, Jungreis CA, Price TR. Lacunar infarcts defined by magnetic resonance imaging of 3660 elderly people: The cardiovascular health study. Arch Neurol. 1998;55(9):1217-25. https://jamanetwork.com/journals/jamaneurology/fullarticle/774257

35. Arauz A, Murillo L, Cantú C, Barinagarrementeria F, Higuera J. Prospective study of single and multiple lacunar infarcts using magnetic resonance imaging: Risk factors, recurrence, and outcome in 175 consecutive cases. Stroke. 2003;34(10):2453-8. https://doi. org/10.1161/01.STR.0000090351.41662.91

36. Arboix A, Font A, Garro C, García-Eroles L, Comes E, Massons J. Recurrent lacunar infarction following a previous lacunar stroke: A clinical 
study of 122 patients. J Neurol Neurosurg Psychiatry. 2007;78(12):1392-4. https://doi.org/10.1136/ jnnp.2007.119776

37. Lee JE, Shin DW, Yun JM, Kim SH, Nam YS, Cho $\mathrm{B}$, et al. Insulin Resistance Is a Risk Factor for Silent Lacunar Infarction. Stroke. 2016;47(12):2938-44. https://doi.org/10.1161/STROKEAHA.116.014097

38. Dearborn JL, Schneider AL, Sharrett AR, Mosley TH, Bezerra DC, Knopman DS, Selvin E, Jack CR, Coker LH, Alonso A, Wagenknecht LE, Windham BG GR. Obesity, Insulin Resistance, and Incident Small Vessel Disease on Magnetic Resonance Imaging: Atherosclerosis Risk in Communities Study. Stroke. 2015;46(11):3131-6. https://doi.org/10.1161/ STROKEAHA.115.010060

39. Mohr JP, Caplan LR, Melski JW, Goldstein RJ, Duncan GW, Kistler JP, et al. The harvard cooperative stroke registry: A prospective registry. Neurology. 1978;28(8):754-62. https://doi.org/10.1212/ wnl.28.8.754

40. Arboix A, Marti-Vilalta JL, Garcia JH. Clinical study of 227 patients with lacunar infarcts. Stroke. 1990;21(6):842-7. https://doi.org/10.1161/01. STR.21.6.842

41. Bezerra DC, Sharrett AR, Matsushita K, Gottesman RF, Shibata D, Mosley TH, et al. Risk factors for lacune subtypes in the Atherosclerosis Risk in Communities (ARIC) study. Neurology. 2012;78(2):102-8. https://doi.org/10.1212/WNL.0b013e31823efc42

42. Shoamanesh A, Pearce LA, Bazan C, Catanese L, Mcclure LA, Sharma M, et al. Microbleeds in the SPS3 Trial: Stroke, Mortality and Treatment Interactions. Ann Neurol. 2017;2(82):196-207. https://doi. org/10.1002/ana.24988

43. Santiago Palacio, Leslie A. McClure, Oscar R. Benavente, Carlos Bazan III PP and, Hart RG. Lacunar strokes in patients with diabetes mellitus: risk factors, infarct location, and prognosis: the secondary prevention of small subcortical strokes study. Stroke. 2014;45(9):2689-94. https://doi.org/10.1161/ STROKEAHA.114.005018

44. Sacco S, Marini C, Totaro R, Russo T, Cerone D, Carolei A. A population-based study of the incidence and prognosis of lacunar stroke. Neurology. 2006;66(9):1335-8. https://doi.org/10.1212/01. wnl.0000210457.89798.0e

45. Bamford J, Sandercock P, Jones L, Warlow C. The natural history of lacunar infarction: The oxfordshire community stroke project. Stroke. 1987;18(3):545-51. https://doi.org/10.1161/01.STR.18.3.545

46. Potter GM, Doubal FN, Jackson CA, Chappell FM, Sudlow CL, Dennis MS, et al. Counting cavitating lacunes underestimates the burden of lacunar infarction. Stroke. 2010;41(2):267-72. https://doi. org/10.1161/STROKEAHA.109.566307
47. Moreau F, Patel S, Lauzon ML, McCreary CR, Goyal M, Frayne R, et al. Cavitation after acute symptomatic lacunar stroke depends on time, location, and MRI sequence. Stroke. 2012;43(7):1837-42. https:// doi.org/10.1161/STROKEAHA.111.647859

48. Defebvre L, Krystkowiak P. Movement disorders and stroke. Rev Neurol (Paris) . 2016;172(8-9):483-7. https://doi.org/10.1016/j.neurol.2016.07.006

49. Inoue M, Kojima Y, Mima T, Sawamoto N, Matsuhashi M, Fumuro T, et al. Pathophysiology of unilateral asterixis due to thalamic lesion. Clin Neurophysiol 2012;123(9):1858-64. https://doi.org/10.1016/j. clinph.2012.01.021

50. Tatu L, Moulin T, Martin V, Monnier G, Rumbach L. Unilateral pure thalamic asterixis: Clinical, electromyographic, and topographic patterns. Neurology. 2000;54(12):2339-42. https://doi.org/10.1212/ WNL.54.12.2339

51. Klos KJ, Wijdicks EFM. Unilateral asterixis after thalamic hemorrhage. Neurology. 2006;66(2). https:// doi.org/10.1212/01.wnl.0000194263.21923.71

52. Li S, Kumar Y, Gupta N, Abdelbaki A, Sahwney H, Kumar A, et al. Clinical and Neuroimaging Findings in Thalamic Territory Infarctions: A Review. J Neuroimaging. 2018;28(4):343-9. https://doi.org/10.1111/ jon. 12503

53. Wilkins RH, Brody IA. The Thalamic Syndrome. Arch Neurol. 1969;20(5):559. https://doi.org/10.1001/ archneur.1969.00480110123014

54. Arboix A, López-Grau M, Casasnovas C, GarcíaEroles L, Massons J, Balcells M. Clinical study of 39 patients with atypical lacunar syndrome. J Neurol Neurosurg Psychiatry. 2006;77(3):381-4. https://doi. org/10.1136/jnnp.2005.071860

55. Glass JD, Levey AI, Rothstein JD. The dysarthria-clumsy hand syndrome: A distinct clinical entity related to pontine infarction. Ann Neurol. 1990;27(5):487-94. https://doi.org/10.1002/ ana.410270506

56. Schmahmann JD, Ko R, MacMore J. The human basis pontis: Motor syndromes and topographic organization. Brain. 2004;127(6):1269-91. https://doi. org/10.1093/brain/awh138

57. Cao L, Guo Y, Zhu Z. Effects of hyperhomocysteinemia on ischemic cerebral small vessel disease and analysis of inflammatory mechanisms. Int J Neurosci. 2020;0(0):1-8. https://doi.org/10.1080/00207454.2020 .1744597

58. Bogousslavsky J, Regli F. Centrum ovale infarcts: subcortical infarction in the superficial territory of the middle cerebral artery. Neurology. 1992;42(10):1992-8. https://doi.org/10.1212/ wnl.42.10.1992

59. Yonemura K, Kimura K, Minematsu K, Uchino M, Yamaguchi T. Small centrum ovale infarcts on 
diffusion-weighted magnetic resonance imaging. Stroke. 2002;33(6):1541-4. https://doi.org/10.1161/01. STR.0000016961.01086.94

60. Fiebach JB, Hopt A, Vucic T, Brunecker P, Nolte CH, Doege $\mathrm{C}$, et al. Inverse mismatch and lesion growth in small subcortical ischaemic stroke. Eur Radiol. 2010;20(12):2983-9. https://doi.org/10.1007/s00330010-1858-8

61. Asdaghi N, Pearce LA, Nakajima M, Field TS, Bazan C, Cermeno F, et al. Clinical correlates of infarct shape and volume in lacunar strokes: The secondary prevention of small subcortical strokes trial. Stroke. 2014;45(10):2952-8. https://doi.org/10.1161/ STROKEAHA.114.005211

62. Gattringer T, Eppinger S, Pinter D, Pirpamer L, Berghold A, Wünsch G, et al. Morphological MRI characteristics of recent small subcortical infarcts. Int J Stroke. 2015;10(7):1037-43. https://doi.org/10.1111/ ijs.12499

63. Pantoni L. Cerebral small vessel disease: from pathogenesis and clinical characteristics to therapeutic challenges. Lancet Neurol. 2010;9(7):689-701. https://doi. org/10.1016/S1474-4422(10)70104-6

64. De Silva TM, Miller AA. Cerebral small vessel disease: Targeting oxidative stress as a novel therapeutic strategy? Front Pharmacol. 2016;7(3):1-18. https://doi.org/10.3389/fphar.2016.00061

65. Li Q, Yang Y, Reis C, Tao T, Li W, Li X, et al. Cerebral Small Vessel Disease. Cell Transplantation. 2018;27(12):1711-22. https://doi. org/10.1177/0963689718795148
Declaration of patient consent: The authors certify that they have obtained all appropriate patient consent forms. In the form the patient(s) has/have given his consent for his images and other clinical information to be reported in the journal.

Acknowledgments and funding: This study was supported by Research Institute of the Technical University of Manabi and Faculty of Health Sciences, Career of Medicine.

Conflict of interest: The authors declare that they have no conflict of interest.

Author statement: Herdoiza M.J: Data cases collected and writing of the manuscript. Fraga B.D: writing of the manuscript. Vizcaino G: review of the manuscript. Siteneski A.: Interpretation of cases, original draft and writing of the manuscript. All authors of this paper have read and approved the final version of submitted manuscript. 